\title{
A case of subacute-onset myelodysplastic syndrome with infection mimicking thrombotic thrombocytopenic purpura: a case report with literature review
}

\author{
Masahiro Okabe*, Daisuke Nakashima, Nanae Matsuo, Yukio Maruyama and Takashi Yokoo
}

\begin{abstract}
Background: Schistocytosis, which is often observed in thrombotic thrombocytopenic purpura (TTP) patients, is a rare complication in myelodysplastic syndrome (MDS) patients.

Case presentation: We report on a 59-year-old man with progressive anemia and thrombocytopenia. Schistocytes were observed in his peripheral blood; consciousness disturbance, renal insufficiency, and fever were subsequently observed, fulfilling the classic pentad of TTP. He also showed massive hematuria, headache, chest pain, and abdominal pain, and brain magnetic resonance imaging scan demonstrated small infarctions. Cefmetazole was not effective, and there was no focus of infection. Disseminated intravascular coagulation (DIC) score was low at that time. We suspected TTP, and therapeutic plasma exchange was initiated. Simultaneously, antibiotic was changed to piperacillin/tazobactam. After the initiation of those treatments, his general condition improved. ADAMTS13 activity did not decrease significantly; therefore, we stopped the therapeutic plasma exchange. His D-dimer level increased and antithrombin level decreased. Heparin treatment was initiated; however, anemia and thrombocytopenia persisted. Bone marrow examinations revealed dyspoiesis in all cell lines, and a complex karyotype indicated a high risk of MDS. His TTP-like condition relapsed; again, piperacillin/tazobactam was effective. Enterococcus faecalis and Haemophilus influenzae were detected in urine culture later. Infection and/or DIC superimposed on MDS might be involved in the pathophysiology of this case.
\end{abstract}

Conclusions: It should be noted that subacute-onset of MDS with infection can mimic TTP.

Keywords: Myelodysplastic syndrome, Schistocyte, Thrombotic thrombocytopenic purpura, Infection, Therapeutic plasma exchange

\section{Background}

Myelodysplastic syndrome(s) (MDS) are a group of clonal bone marrow neoplasms characterized by ineffective hematopoiesis. They manifest via morphologic dysplasia in hematopoietic cells as well as by peripheral cytopenia(s) [1]. Schistocytes, which are characteristic of microangiopathic hemolytic anemia (MAHA), are a rare complication in MDS patients.

\footnotetext{
* Correspondence: mokabe@jikei.ac.jp

Division of Nephrology and Hypertension, Department of Internal Medicine The Jikei University School of Medicine, 3-25-8 Nishi-Shimbashi, Minato-ku, Tokyo 105-8461, Japan
}

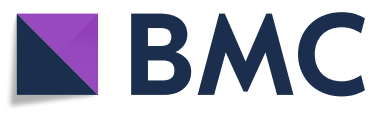

(c) The Author(s). 2019 Open Access This article is distributed under the terms of the Creative Commons Attribution 4.0 International License (http://creativecommons.org/licenses/by/4.0/), which permits unrestricted use, distribution, and reproduction in any medium, provided you give appropriate credit to the original author(s) and the source, provide a link to the Creative Commons license, and indicate if changes were made. The Creative Commons Public Domain Dedication waiver (http://creativecommons.org/publicdomain/zero/1.0/) applies to the data made available in this article, unless otherwise stated. life-threatening thrombotic microangiopathy (TMA), associated with MAHA, thrombocytopenia, and thrombi-associated involvement in organs such as the brain, kidney, and heart [2]. A deficiency in ADAMTS13 activity is specific to TTP and is a requirement for a diagnosis of TTP; however, the test for ADAMTS13 activity takes several days. Performing therapeutic plasma exchange (PEX) early is critical when treating TTP. It should be initiated as a first-line treatment by physicians suspecting TTP from clinical symptoms in an emergency setting.

In this report, we present the case of a man with subacute-onset of MDS complicated with infection, 
which was initially difficult to distinguish from TTP. This was due to his symptoms matching the classic pentad of TTP (MAHA, thrombocytopenia, renal insufficiency, mental status changes, and fever).

\section{Case presentation}

A 59-year-old man with diabetes mellitus, chronic kidney disease, hypertension, hyperuricemia, dyslipidemia, and anxiety neurosis developed anemia. Over 1 month, the concentration of hemoglobin $(\mathrm{Hb})$ decreased from 13.6 to $9.3 \mathrm{~g} / \mathrm{dL}$. An upper gastrointestinal endoscopy and colon fiberscopy demonstrated no abnormalities. One month later, in addition to developing anemia $(\mathrm{Hb} 6.9 \mathrm{~g} / \mathrm{dL})$, his platelet count decreased from $210,000 / \mathrm{mm}^{3}$ to $103,000 /$ $\mathrm{mm}^{3}$. He was admitted to our hospital for acute anemia and thrombocytopenia. He was afebrile, and his blood pressure and heart rate were $146 / 70 \mathrm{mmHg}$ and $66 / \mathrm{min}$, respectively. Upon physical examination, he demonstrated no remarkable findings other than slight bilateral leg edema. Laboratory findings were summarized in Table 1 . He had anemia and thrombocytopenia, but serum iron level, total iron-binding capacity, ferritin level, vitamin $\mathrm{B}_{12}$ level, folate level, and coagulation tests were normal. $\mathrm{He}$ demonstrated renal insufficiency, the cause of which may have been a diabetic nephropathy because he had a 40-year history of diabetes mellitus, diabetic retinopathy, and normal-sized kidneys with no evidence of hematuria or abnormalities in immunoglobulin or complement levels. He had been treated with sitagliptin, olmesartan, azelnidipine, benzbromarone, and lorazepam for more than 1 year, and began taking atorvastatin 1 month before the onset of anemia.

Drug-induced bicytopenia was suspected; therefore, all drugs were withdrawn. Some improvement was observed with regard to anemia and thrombocytopenia ( $\mathrm{Hb} 8.1 \mathrm{~g} /$ $\mathrm{dL}$ and platelet count $94,000 / \mathrm{mm}^{3}$ ) (Fig. 1). However, schistocytes were observed on a peripheral blood smear (Fig. 2). Simultaneously, the patient developed anemia and thrombocytopenia $(\mathrm{Hb} 6.2 \mathrm{~g} / \mathrm{dL}$ and platelet count $57,000 / \mathrm{mm}^{3}$ ), disturbance of consciousness, a worsened renal insufficiency (serum creatinine level of $1.85 \mathrm{mg} / \mathrm{dL}$ and estimated glomerular filtration rate of $30.7 \mathrm{~mL} / \mathrm{min} /$ $1.73 \mathrm{~m}^{2}$ ) with massive hematuria, and fever. Moreover, he complained of headaches, chest pain, and abdominal pain. The fragmented RBC rate was $1.8-2.8 \%$ of total RBC count. The concentration of serum lactate dehydrogenase (LDH) and indirect bilirubin increased to $421 \mathrm{IU} /$ $\mathrm{L}$ and $1.4 \mathrm{mg} / \mathrm{dL}$, respectively. Direct and indirect Coombs' tests were negative. Prothrombin time (PT), PT- international normalized ratio (INR), partial thromboplastin time, fibrinogen level, fibrin degradation products level, and D-dimer level were $75 \%, 1.1,37.2 \mathrm{~s}$,

Table 1 Baseline laboratory findings

\begin{tabular}{|c|c|c|c|c|c|}
\hline \multicolumn{6}{|l|}{ Blood } \\
\hline WBC count & $5900 / \mathrm{mm}^{3}$ & AST & $22 \mathrm{U} / \mathrm{L}$ & CRP & $0.11 \mathrm{mg} / \mathrm{dL}$ \\
\hline RBC count & $2.59 \times 10^{6} / \mathrm{mm}^{3}$ & ALT & $33 \mathrm{U} / \mathrm{L}$ & $\mathrm{Fe}$ & $97 \mu \mathrm{g} / \mathrm{dL}$ \\
\hline Hemoglobin & $6.7 \mathrm{~g} / \mathrm{dL}$ & $\mathrm{LDH}$ & $340 \mathrm{U} / \mathrm{L}$ & $\mathrm{TIBC}$ & $237 \mu \mathrm{g} / \mathrm{dL}$ \\
\hline Hematocrit & $21.6 \%$ & ALP & $151 \mathrm{U} / \mathrm{L}$ & Ferritin & $271 \mathrm{ng} / \mathrm{mL}$ \\
\hline MCV & $83.4 \mathrm{fL}$ & Total bilirubin & $0.8 \mathrm{mg} / \mathrm{dL}$ & Vitamin $B_{12}$ & $873 \mathrm{pg} / \mathrm{mL}$ \\
\hline $\mathrm{MCH}$ & $25.9 \mathrm{pg}$ & Indirect bilirubin & $0.7 \mathrm{mg} / \mathrm{dL}$ & Folate & $3.0 \mathrm{ng} / \mathrm{mL}$ \\
\hline $\mathrm{MCHC}$ & $31.0 \mathrm{~g} / \mathrm{dL}$ & Total protein & $6.6 \mathrm{~g} / \mathrm{dL}$ & Glycoalbumin & $16.6 \%$ \\
\hline Platelet count & $84,000 / \mathrm{mm}^{3}$ & Albumin & $4.0 \mathrm{~g} / \mathrm{dL}$ & Antinuclear antibody (IF) & Negative \\
\hline Reticulocytes & $95,300 / \mathrm{mm}^{3}(3.7 \%)$ & BUN & $15 \mathrm{mg} / \mathrm{dL}$ & $\lg G$ & $1237 \mathrm{mg} / \mathrm{dL}$ \\
\hline PT & $90 \%$ & Creatinine & $1.35 \mathrm{mg} / \mathrm{dL}$ & $\lg A$ & $284 \mathrm{mg} / \mathrm{dL}$ \\
\hline APTT & $28.8 \mathrm{~s}$ & eGFR & $43.3 \mathrm{~mL} / \mathrm{min} / 1.73 \mathrm{~m}^{2}$ & $\lg M$ & $32 \mathrm{mg} / \mathrm{dL}$ \\
\hline Fibrinogen & $312 \mathrm{mg} / \mathrm{dL}$ & $\mathrm{Na}$ & $140 \mathrm{mEq} / \mathrm{L}$ & $\mathrm{C3}$ & $101 \mathrm{mg} / \mathrm{dL}$ \\
\hline FDP & $3 \mu \mathrm{g} / \mathrm{mL}$ & K & $4.1 \mathrm{mEq} / \mathrm{L}$ & C4 & $32 \mathrm{mg} / \mathrm{dL}$ \\
\hline D-dimer & $0.8 \mu \mathrm{g} / \mathrm{mL}$ & $\mathrm{Cl}$ & $112 \mathrm{mEq} / \mathrm{L}$ & $\mathrm{CH} 50$ & $50.7 \mathrm{U} / \mathrm{mL}$ \\
\hline \multicolumn{6}{|l|}{ Urine } \\
\hline $\mathrm{pH}^{*}$ & 5.5 & $\mathrm{RBC}$ & $0-1 / \mathrm{HPF}$ & $24 \mathrm{~h}$ creatinin clearance & $61 \mathrm{~mL} / \mathrm{min}$ \\
\hline Glucose* & Negative & WBC & $1-4 / \mathrm{HPF}$ & Urinary protein exertion & $944 \mathrm{mg} / \mathrm{d}$ \\
\hline Ketone* & Negative & & & & \\
\hline
\end{tabular}

*Dipstick tests

WBC white blood cell, RBC red blood cell, $M C V$ mean corpuscular volume, $M C H$ mean corpuscular hemoglobin, $M C H C$ mean corpuscular hemoglobin concentration, $P T$ prothrombin time, APTT activated partial thromboplastin time, FDP fibrin degradation products, AST aspartate transaminase, $A L T$ alanine aminotransferase, $L D H$ lactate dehydrogenase, $A L P$ alkaline phosphatase, $B U N$ blood urea nitrogen, eGFR estimated glomerular filtration rate, $C R P C$-reactive protein, TIBC total iron binding capacity, IF immunofluorescent, Ig immunoglobulin, HPF high power field 


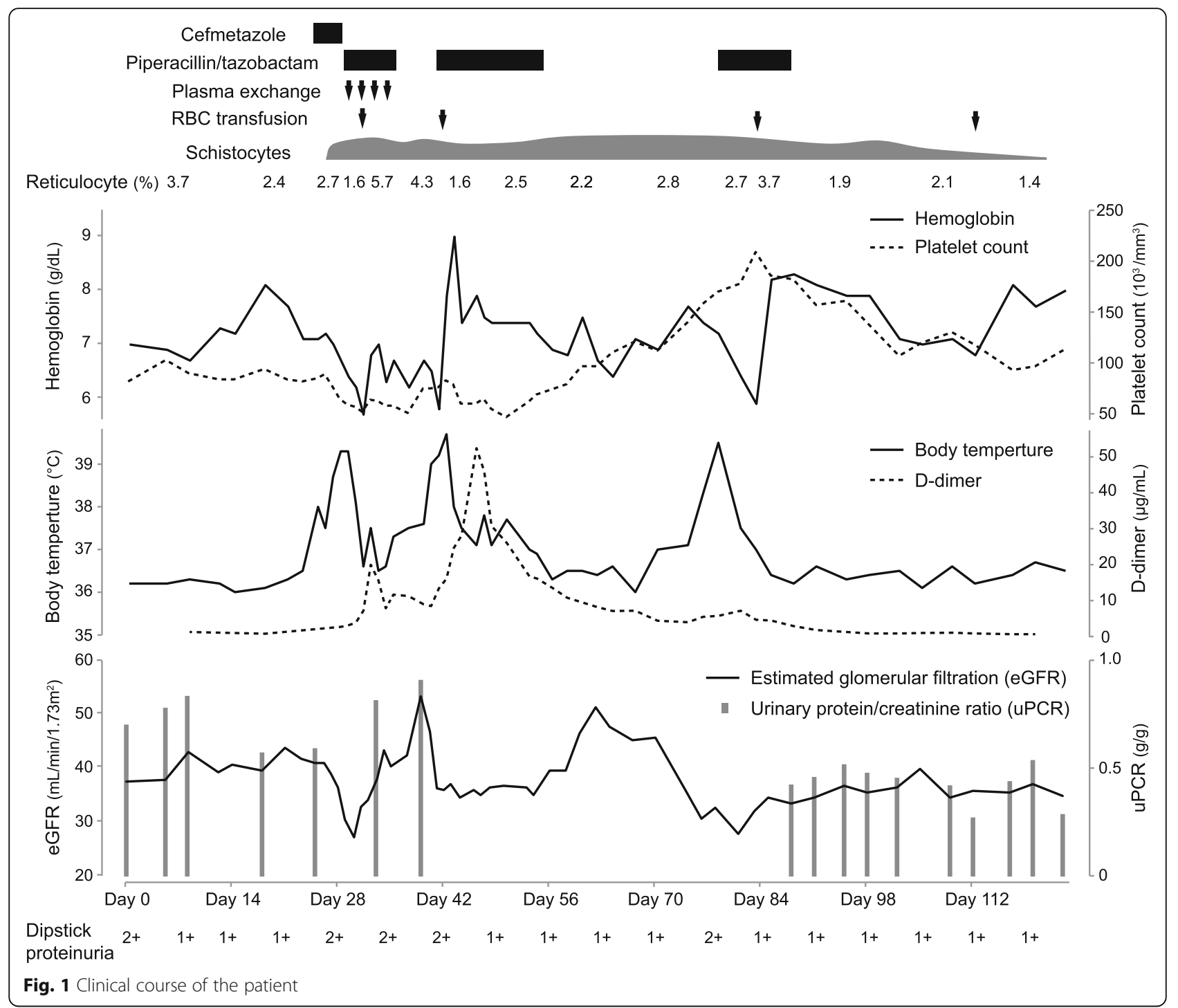

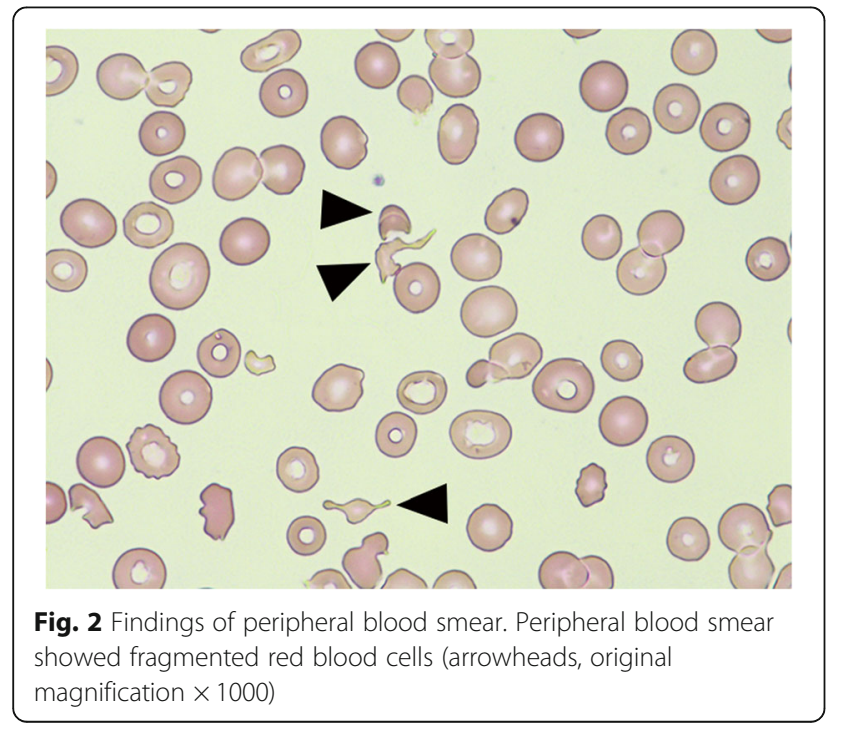

$771 \mathrm{mg} / \mathrm{dL}, \quad 8 \mu \mathrm{g} / \mathrm{mL}$, and $2.7 \mu \mathrm{g} / \mathrm{mL}$, respectively. C-reactive protein level and procalcitonin level were $19.6 \mathrm{mg} / \mathrm{dL}$ and $0.66 \mathrm{ng} / \mathrm{mL}$, respectively. Computed tomography (CT) scanning of the brain, chest, and abdomen; urinalysis; and cerebrospinal fluid examination did not detect obvious infections. Interferon-gamma release assay and serum $\beta$-D-glucan assay were negative. Heart murmurs were not audible, and neither valve vegetation nor valve regurgitation was observed on transthoracic echocardiography. Subconjunctival hemorrhage, endophthalmitis, Roth spots, Osler nodes, or Janeway lesions were not observed. Although no obvious nervous system abnormalities were noted, a transient conscious disturbance was observed, and a brain magnetic resonance imaging scan demonstrated small infarctions (Fig. 3). The administration of cefmetazole did not improve his condition. While the International Society of Thrombosis and Hemostasis disseminated intravascular coagulation (DIC) 

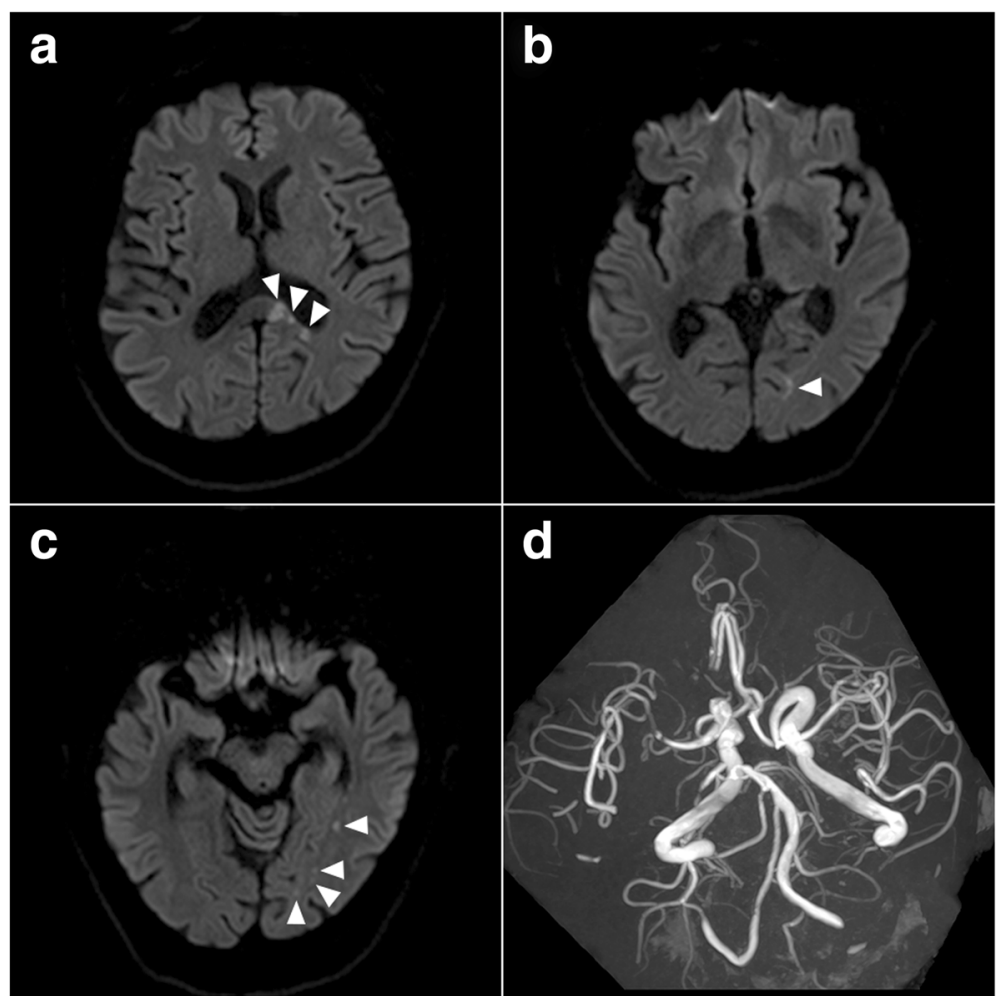

Fig. 3 Findings of magnetic resonance imaging and angiography. a-c Multiple cerebral infarctions were observed on diffusion weighted imaging (arrowheads). d Magnetic resonance angiography revealed stenosis of the right middle cerebral artery and bilateral posterior cerebral arteries

score was low ( 3 points) at that time, the patient had a PLASMIC score of 6; the criteria "hemolysis variable," "no active cancer," "no history of solid-organ or stem-cell transplant," "mean corpuscular volume < $90 \mathrm{fL}$," "PT-INR $<1.5$," and "creatinine $<2.0 \mathrm{mg} / \mathrm{dL}$ " were positive, and "platelet count $<30000 / \mathrm{mm}^{3}$ " was negative $[3,4]$. The PLASMIC score is a recently reported scoring system for predicting a deficiency in ADAMTS13 activity. A high score (6 or 7) indicates a deficiency in ADAMTS13 activity and is associated with approximately $90 \%$ sensitivity and specificity $[3,4]$. These findings implied the possibility of TTP, and as such, PEX was started. We planned to exchange 1.2 plasma volumes with fresh frozen plasma; however, for the allergic reaction, 0.85 plasma volumes (approximately $3 \mathrm{~L}$ ) were replaced per PEX procedure. Due to a possibility of cefmetazole-resistant bacterial infection, cefmetazole was changed to piperacillin/tazobactam. After the initiation of those treatments, the patient's overall condition quickly improved. Test results for ADAMTS13 activity and haptoglobin level were obtained after 4 rounds of PEX, and no significant decrease was observed for the 2 measures $(61.2 \%$ and $49 \mathrm{mg} / \mathrm{dL}$, respectively). Therefore, PEX was ceased at this time. No apparent causes for secondary TMA were detected by additional tests (Table 2). During the treatment, his D-dimer level increased significantly $(>20 \mu \mathrm{g} / \mathrm{mL})$.
Enhanced CT of the chest, abdomen, and legs did not demonstrate any apparent thrombi; therefore, DIC was suspected, and heparin treatment was administered. His antithrombin level decreased (52\%). Cultures of blood, urine, stool, and cerebrospinal fluid were negative, and thus, antibiotic treatment was also stopped. His renal insufficiency improved; however, his anemia with schistocytes and thrombocytopenia persisted.

Bone marrow aspiration and biopsy were performed and revealed hypercellular marrow, mononuclear megakaryocytes, dysgranulopoiesis with hypogranulation and abnormal size, and dyserythropoiesis with nuclear fragmentation, multinuclearity, and megaloblastoid changes (Fig. 4a-c). There was no increase in blasts. Karyotype analysis revealed a complex karyotype (43XY, $-5,-16$, add (17)(p11), - 18, - 19, - 20, + mar1, + mar2, 2 3dmin, Fig. 4d). Based on these findings, the patient was diagnosed as having MDS.

One week later, he presented with fever, alteration of consciousness, development of anemia and thrombocytopenia, and renal insufficiency again. Procalcitonin level was increased $(3.72 \mathrm{ng} / \mathrm{mL})$; his condition improved only by treatment with piperacillin/tazobactam. Causative microorganisms were not detected at that time; however, Enterococcus faecalis and Haemophilus influen$z a e$, which were resistant to cephem antibiotics but 
Table 2 Examinations for differential diagnosis of primary and secondary thrombotic microangiopathy

\begin{tabular}{llll}
\hline Blood & & & \\
ADAMTS13 & $61.2 \%$ & Anti-cardiolipin antibody & $12 \mathrm{U} / \mathrm{mL}$ \\
ADAMTS13 inhibitor & $<0.5 \mathrm{BU} / \mathrm{mL}$ & Lupus anticoagulant & 1.2 \\
Anti-lipopolysaccharide antibody & Negative & CMV antigenemia (C10/11) & Negative \\
Anti-dsDNA antibody & $<10 \mathrm{U} / \mathrm{mL}$ & CMV IgM & 0.27 (negative) \\
Anti-Sm antibody & $<2.0 \mathrm{U} / \mathrm{mL}$ & EBV VCA IgG & $40 \times$ \\
Anti-SS-A antibody & $<1.0 \mathrm{U} / \mathrm{mL}$ & EBV VCA IgM & $<10 \times$ \\
Anti-SS-B antibody & $<1.0 \mathrm{U} / \mathrm{mL}$ & EBV EBNA & $10 \times$ \\
Anti-RNP antibody & $<2.0 \mathrm{U} / \mathrm{mL}$ & Influenza A virus & $<4 \times$ \\
Anti-centromere antibody & $<5.0$ & Influenza B virus & $<4 \times$ \\
Anti-Scl-70 antibody & $<1.0 \mathrm{U} / \mathrm{mL}$ & HIV-1/HIV-2 antibodies & Negative \\
Anti-JO-1 antibody & $<1.0 \mathrm{U} / \mathrm{mL}$ & HIV-1 p24 antigen & Negative \\
MPO-ANCA & $<1.0 \mathrm{U} / \mathrm{mL}$ & VZV IgG & 28.8 (positive) \\
PR3-ANCA & $<1.0 \mathrm{U} / \mathrm{mL}$ & VZV IgM & 0.23 (negative) \\
Anti-GBM antibody & $<2.0 \mathrm{U} / \mathrm{mL}$ & Parvovirus B19 IgM & $<0.8$ \\
Feces & & & \\
Shiga toxin & Negative & & \\
\hline GBM glomerular basement membrane, CMV cytomegalovirus, EBV Epstein-Barr virus, VCA viral capsid antigen, EBNA EB nuclear antigen, VZV varicella zoster virus
\end{tabular}

susceptible to piperacillin/tazobactam, grew in his urine culture 3 weeks later, when he presented with fever again and was treated with piperacillin/tazobactam. Schistocytes were continuously observed (1.8 to $2.8 \%$ of total $\mathrm{RBC}$ count) even after his infection improved.

As a high D-dimer level persisted $(>5 \mu \mathrm{g} / \mathrm{mL})$ and deep vein thrombosis of his left lower leg was revealed by ultrasound examination, treatment with edoxaban was initiated. D-dimer level returned to normal after 2 months. Finally, schistocytes were no longer observed on peripheral blood smears.

The patient's Revised International Prognostic Scoring System (IPSS-R) score was 6, which is indicative of being in the high-risk group [5]. Although the patient was recommended to undergo allogeneic stem cell transplantation or treatment with azacytidine therapy, he and his sister refused these treatments, and he was transferred to a recuperation hospital. One month later, he died of infection, the origin of which was unknown.

\section{Discussion and conclusions}

We described a man with subacute-onset and high-risk MDS who presented with schistocytosis, a rare complication in MDS patients. His symptoms and laboratory data mimicked TTP, but these presentations were believed to be exaggerated by the bacterial infection and DIC.

Schistocytosis occurs in various diseases such as metastatic cancer, malignant hypertension, DIC, and TMAs [6]. However, schistocytosis in MDS patients is rare; to the best of our knowledge, only eight cases have been reported [7-13]. We reviewed all previously reported cases, and the characteristics of these are summarized in Table 3. Most of these cases showed anemia, thrombocytopenia, and the increase of serum LDH and bilirubin, as well as our case. While the cause of schistocytosis was not detected in three cases, three other cases were complicated with TTP.

Acute-onset of schistocytosis, occult infection, and initially low DIC score complicated the present case. The present patient demonstrated anemia with schistocytes, thrombocytopenia, worsened renal insufficiency, conscious disturbance, and fever, which are known as classical pentad of TTP, which is a medical emergency and prompt diagnosis and treatment are critical. The patient's PLASMIC score was 6 , which is predictive of < $10 \%$ of ADAMTS13 activity [3, 4]. Infection was not clear, and the DIC score was low at that time. He presented with headache, chest pain, and abdominal pain, which led to a suspicion of microvascular thrombi by TTP. The brain magnetic resonance imaging scan revealed small infarctions. Infective endocarditis and cardiac thrombosis were unlikely. These findings indicated a high possibility of TTP, and as such, PEX was performed until it was apparent that there was no ADAMTS13 deficiency.

The treatment with piperacillin/tazobactam improved the patient several times. His D-dimer level increased significantly, and his antithrombin level decreased, indicating the complication of DIC induced by infection. However, schistocytes were observed before the D-dimer level was increased, and TMA-like symptoms might not be explained by only DIC. Shiga toxin-producing 

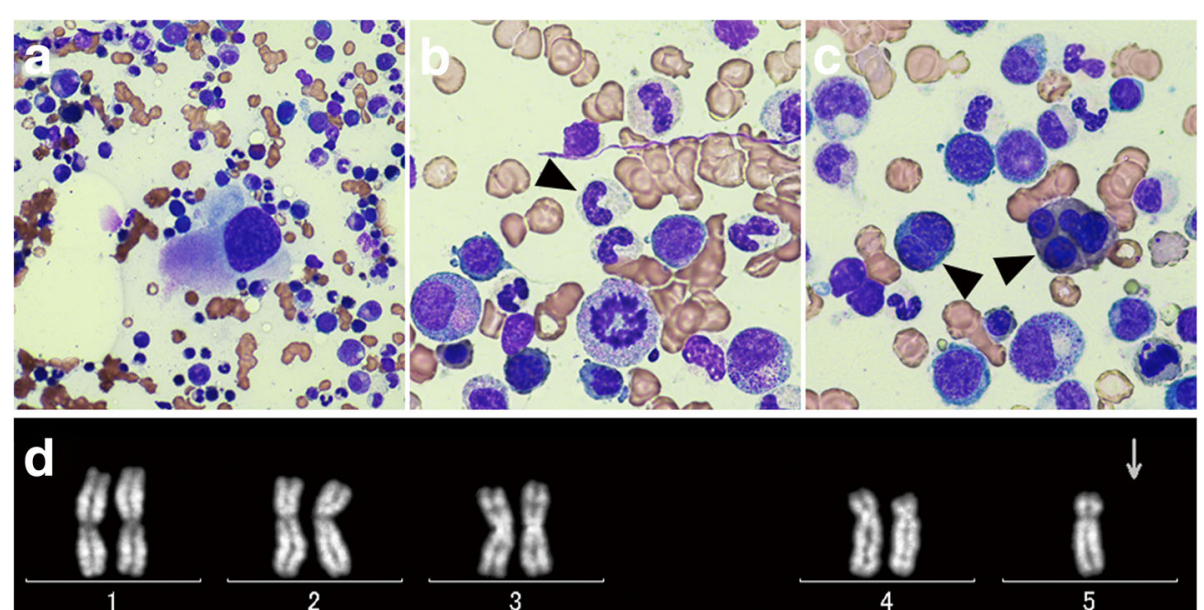

1

2

3

4
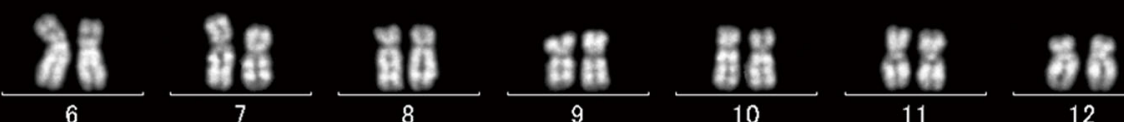

9

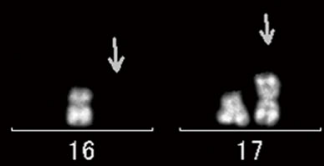

12

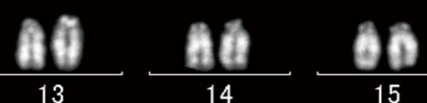

14

15

16

17
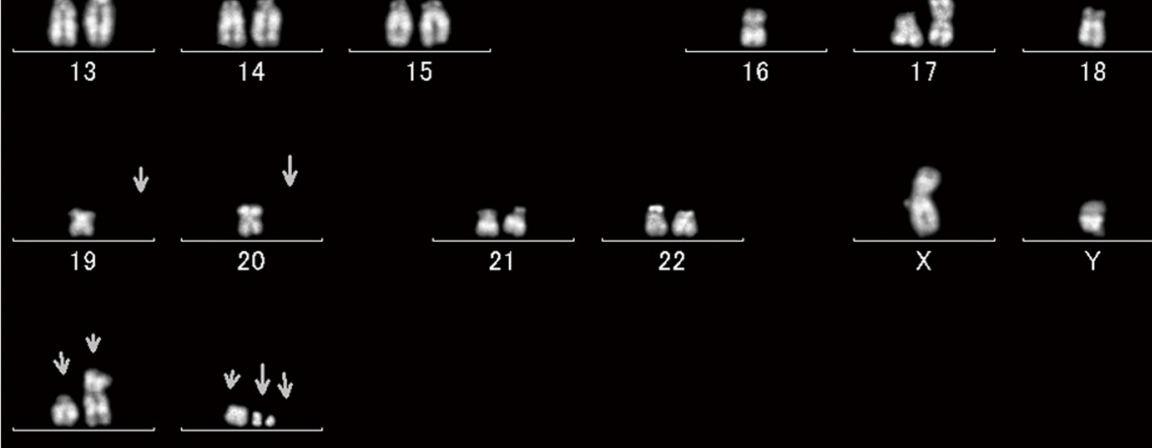

Fig. 4 Findings of bone marrow aspiration. a-c Bone marrow aspiration showed mononuclear megakaryocyte (a, original magnification $\times 400$ ), hypogranular neutrophil $(\mathbf{b}$, arrowhead, original magnification $\times 1000)$, and multinuclear erythroblast $(\mathbf{c}$, arrowheads, original magnification $\times$ 1000). d Karyotype analysis of bone marrow demonstrated a complex karyotype $(43 X Y,-5,-16$, add $(17)(\mathrm{p} 11),-18,-19,-20,+$ mar1, + mar2, 2 3dmin)

Table 3 Case reports regarding schistocytosis in myelodysplastic syndrome patients

\begin{tabular}{|c|c|c|c|c|c|c|c|}
\hline Authors (reference) & Age & Sex & $\mathrm{Hb}(\mathrm{g} / \mathrm{dL})$ & Platelet count $\left(10^{3} / \mathrm{mm}^{3}\right)$ & $\mathrm{LDH}(\mathrm{U} / \mathrm{L})$ & Total bilirubin (mg/dL) & Cause of schistocytosis \\
\hline Hartz et al. [7] & 78 & Male & 10.6 & Normal & 380 & 1.4 & Unknown \\
\hline Rummens et al. [8] Case 1 & 60 & Male & 10.3 & 46 & 353 & 0.9 & Unknown \\
\hline Rummens et al. [8] Case 2 & 59 & Male & 12 & 116 & N/A & N/A & Unknown \\
\hline Leone et al. [9] & 20 & Male & 4.7 & 30 & N/A & 4 & TTP \\
\hline Doudenko-Pirozzolo et al. [10] & 20 & Male & 5.5 & 3 & 2505 & 4.6 & TTP \\
\hline Sasaki et al. [11] & 21 & Female & 7.3 & 20 & 453 & 2.2 & TTP \\
\hline Zahid et al. [12] & 70 & Female & 6.2 & 57 & 683 & 3.7 & MAHA \\
\hline Moscoso Martinez et al. [13] & 66 & Female & 6.6 & 77 & 1248 & 1.4 & Infection \\
\hline The present case & 59 & Male & 5.7 & 52 & 421 & 1.7 & Infection \\
\hline
\end{tabular}


Escherichia coli hemolytic uremic syndrome, which is another cause of primary TMA, was unlikely because of no evidence of fecal Shiga toxin or serum anti-lipopolysaccharide antibodies. Collagen diseases such as systemic lupus erythematosus, ANCA-related vasculitis, or viral infections such as HIV and cytomegalovirus were also unlikely on the basis of serological findings and because of a lack of obvious symptoms. Although $\mathrm{C} 3, \mathrm{C} 4$, and $\mathrm{CH} 50$ levels were not decreased, as detailed complement functional examinations were not possible in our hospital, complement-mediated hemolytic uremic syndrome could not be fully ruled out. Bacterial infections also can cause TMA, and TMA-like symptoms such as chest pain, abdominal pain, and headache improved upon treatment with piperacillin/tazobactam in this case. Among previously reported eight cases of MDS with schistocytosis, one case was associated with infection [13]. Notably, as in our case, the MDS patient with infection-associated schistocytes presented with the classical pentad of TTP, but ADAMTS13 activity was not decreased. In this regard, infection and/ or DIC might be involved in the pathophysiology of this case.

By the means of bone marrow examinations and the karyotype analysis, the patient was finally diagnosed as having high-risk MDS. Patients with MDS have a high incidence of infection, which is the most common cause of death during MDS [14]. This is the result of neutropenia in addition to granulocyte dysfunction [15]. This patient did not have neutropenia; however, degranulation and size abnormalities in granulocytes were observed, which may in turn be related to granulocyte dysfunction. Infections are sometimes occult in MDS patients [16], and the focus of infection was not obvious in this case at first. Urinary bacterial infection was detected later.

As magnetic resonance angiography showed the stenosis of cerebral arteries, multiple brain infarctions might be caused by artery-to-artery embolism or hypoperfusion of the brain because of infection. Septic embolism is also a possible cause of multiple brain infarctions; however, no pathogen was detected on repeated blood cultures, and cardiac valve vegetation was not observed. Also, cerebral abscesses and microaneurysms were absent, and the cerebrospinal fluid culture was negative; therefore, septic embolism might be unlikely.

Schistocytosis continued for 2 months after the infection improved with antibiotics. Chronic renal failure has also been reported as a cause of schistocytosis [17]. However, as schistocytes disappeared after the D-dimer level dropped within the normal range as a result of anticoagulant therapy for deep vein thrombosis, blood coagulation disorder might affect the formation of schistocytes in the present case.
Whenever an infection occurred, the patient showed renal insufficiency and a disturbance of consciousness. These might be affected by the preexistence of chronic kidney disease and a mental disorder as well as high fever.

In summary, we report a case of subacute-onset MDS with infection, which was initially difficult to distinguish from TTP.

\section{Abbreviations \\ CT: Computed tomography; DIC: Disseminated intravascular coagulation; Hb: Hemoglobin; LDH: Lactate dehydrogenase; MAHA: Microangiopathic hemolytic anemia; MDS: Myelodysplastic syndrome; PEX: Plasma exchange; PT- INR: Prothrombin time-international normalized ratio; RBC: Red blood cell; \\ TMA: Thrombotic microangiopathy; TTP: Thrombotic thrombocytopenic purpura}

\section{Acknowledgements}

Not applicable

Funding

The authors declare that there is no funding related to this manuscript.

Availability of data and materials

All data analyzed during this study are included in this published article.

Authors' contributions

MO, DN, NM, YM, and TY analyzed and interpreted the patient data. MO drafted the manuscript and is responsible for the final version of the manuscript. All authors read and approved the final manuscript.

Ethics approval and consent to participate

The case report was written in compliance with the Declaration of Helsinki.

Consent for publication

Written informed consent was obtained from the patient for the publication of this case report.

\section{Competing interests}

The authors declare that they have no competing interests.

\section{Publisher's Note}

Springer Nature remains neutral with regard to jurisdictional claims in published maps and institutional affiliations.

Received: 17 January 2019 Accepted: 22 March 2019

Published online: 03 April 2019

\section{References}

1. Arber DA, Orazi A, Hasserjian R, Borowitz MJ, Le Beau MM, Bloomfield CD, et al. The 2016 revision to the World Health Organization classification of myeloid neoplasms and acute leukemia. Blood. 2016;127:2391-406.

2. Joly BS, Coppo P, Veyradier A. Thrombotic thrombocytopenic purpura. Blood. 2017;129:2836-46

3. Bendapudi PK, Hurwitz S, Fry A, Marques MB, Waldo SW, Li A, et al. Derivation and external validation of the PLASMIC score for rapid assessment of adults with thrombotic microangiopathies: a cohort study. Lancet Haematol. 2017:4:e157-64.

4. Li A, Khalighi PR, Wu Q, Garcia DA. External validation of the PLASMIC score: a clinical prediction tool for thrombotic thrombocytopenic purpura diagnosis and treatment. J Thromb Haemost. 2018;16:164-9.

5. Greenberg $P$, Tuechler $H$. Revised international prognostic scoring system for myelodysplastic syndromes. Blood. 2012;120:2454-65.

6. Zini G, d'Onofrio G, Briggs C, Erber W, Jou JM, Lee SH, et al. ICSH recommendations for identification, diagnostic value, and quantitation of schistocytes. Int J Lab Hematol. 2012;34:107-16.

7. Hartz JW, Buss DH, White DR, Bond MG, Scharyj M. Marked elliptocytosis and schistocytosis in hematopoietic dysplasia. Am J Clin Pathol. 1984;82: 354-9. 
8. Rummens JL, Verfaillie C, Criel A, Hidajat M, Vanhoof A, Van Den Berghe H, et al. Elliptocytosis and schistocytosis in myelodysplasia: report of two cases, Acta Haematol. 1986;75:174-7.

9. Leone G, Sica S, De Stefano V, Teofili L, Larocca LM, D'Onofrio G, et al. Acute onset of juvenile myelodysplastic syndrome mimicking thrombotic thrombocytopenic purpura and rapidly evolving in overt myeloid leukemia. Am J Hematol. 1992;41:64-5.

10. Doudenko-Pirozzolo I, Booth R. Pathologic quiz case: a 20-year-old man with a history of hemoptysis and purpura. Arch Pathol Lab Med. 2001;125: 835-7.

11. Sasaki N, Kuroda J, Kawata E, Akaogi T, Kiyota M, Kobayashi Y, et al. Thrombotic thrombocytopenic purpura associated with myelodysplastic syndrome. Int J Hematol. 2008:88:457-9.

12. Zahid MF, Khan N, Pei J, Testa JR, Dulaimi E. Genomic imbalances in peripheral blood confirm the diagnosis of myelodysplastic syndrome in a patient presenting with non-immune hemolytic anemia. Leuk Res Reports. 2016:5:23-6.

13. Moscoso Martínez SF, Polanco Jácome EC, Guevara E, Mattoo V. Myelodysplastic syndrome clinically presenting with the "classic TTP pentad". Case Rep Hematol. 2017;2017:4619406.

14. Pomeroy C, Oken MM, Rydell RE, Filice GA. Infection in the myelodysplastic syndromes. Am J Med. 1991;90:338-44.

15. Boogaerts MA, Nelissen V, Roelant C, Goossens W. Blood neutrophil function in primary myelodysplastic syndromes. Br J Haematol. 1983;55:217-27.

16. Williamson PJ, Oscier DG, Mufti GJ, Hamblin TJ. Pyogenic abscesses in the myelodysplastic syndrome. BMJ. 1989:299:375-6.

17. Huh HJ, Chung JW, Chae SL. Microscopic schistocyte determination according to International Council for Standardization in hematology recommendations in various diseases. Int J Lab Hematol. 2013;35:542-7.

Ready to submit your research? Choose BMC and benefit from:

- fast, convenient online submission

- thorough peer review by experienced researchers in your field

- rapid publication on acceptance

- support for research data, including large and complex data types

- gold Open Access which fosters wider collaboration and increased citations

- maximum visibility for your research: over $100 \mathrm{M}$ website views per year

At $\mathrm{BMC}$, research is always in progress.

Learn more biomedcentral.com/submissions 